\title{
Videoperformance: límites, modalidades y prácticas del cuerpo en la imagen en movimiento
}

\author{
Ana Sedeño Valdellós \\ (Universidad de Málaga)
}

Recibido: 16/7/2012

Aceptado: 20/5/2013

Resumen: La performance se ha caracterizado por una utilización del cuerpo como soporte y materia artística para la construcción de la identidad (sexual, social, étnica...), como modo de representación del humano como ser social y medio en la relación con el otro. Pronto nació la práctica del videoperformance, una modalidad artística que combina dos medios: el vídeo como medio audiovisual entendido bajo una concepción de creación activa y el cuerpo como soporte para la reflexión sobre la identidad y el arte.

Palabras clave: Performance / videoperformance / vídeo de creación / cuerpo en el arte

\section{Videoperformance: Limits, modes and practices of body in moving image}

AвSTRACT: Performance art has been characterized by use of the body as artistic material and support for the construction of identity (sexual, social, ethnic...), as a symbol of the human being like a social being, and like a media in relation to the other one. Soon came the practice of videoperformance, an artistic practice that combines two main media in contemporary creation: the video image, as an audiovisual support within a context of active creation and body as a way for reflection on identity and art.

Keywords: Performance / videoperformance / videoarte / body in art 


\section{El videoperformance: Modalidad de la videocreación}

$\mathrm{E}$ 1 videoarte, una manifestación artística surgida de la televisión, nació y se desarrolló gracias a la comercialización de los versátiles, manejables y económicamente asequibles primeros magnetoscopios $\mathrm{y}$ de las ligeras cámaras portátiles. Este nuevo formato se convirtió en el soporte más adecuado para la creación y experimentación en todo un campo multidisciplinar formado por artistas procedentes de la pintura, la música, la escultura, el teatro y el performance...

El vídeo de creación o videoarte comprendió, desde el principio, todas las prácticas experimentales que utiliza el vídeo como material plástico, un extenso conjunto de acciones y tipos de obras artísticas entre las que se encuentran las videoinstalaciones, las videoperformances, los videoambientes, las videoesculturas (en general, cualquier tipo de dispositivo vídeo en combinación con cualquier práctica artística).

Desde sus inicios, la principal preocupación del videoarte se centró en una intensa innovación del lenguaje y la experimentación formal y en la profundización en las características creativas del medio electrónico, como el manejo creativo del espacio y el tiempo y su percepción por el espectador. A los videoartistas les interesa principalmente la idea más que la obra, una herencia del arte conceptual. La obra de arte es una acción o una idea y adquiere incluso vida propia: la realidad se nos impone.

Esta nueva manifestación artística surgió en una época, los años sesenta, de grandes transformaciones sociales, políticas y culturales, en la que el arte pop revive todo el repertorio iconográfico prestando especial atención a los productos de la sociedad de consumo, el mundo publicitario y los medios de comunicación de masas. Todo un espíritu de ruptura e innovación animaba estas prácticas que abogaban por la transfiguración de la pasividad televisiva en una «creación activa», en palabras del fundador de estas prácticas, el músico Nam June Paik. «El punto de partida del video de creación es elevar a condición artística uno de los mayores símbolos del desarrollo tecnológico y de la sociedad de consumo, el televisor» (Pérez 1991: 23).

El vídeo y la estética de la imagen electrónica se nutrieron de las principales tendencias y manifestaciones de las últimas vanguardias. El vídeo adoptó del arte pop algunas de sus técnicas de acumulación de lenguajes diferentes (cómic, pintura, publicidad, todo lo relacionado con el consumo y con los medios de comunicación...), la seriación y repetición, la confrontación y mezcla de imágenes anacrónicas y estilos contrapuestos, de distintas épocas y lugares. 


\section{El cuerpo como problema para el arte y las ciencias sociales}

Por su parte, la emergencia del cuerpo como material y sustrato metodológico para la creación artística, su relevancia y el lugar central que ha conseguido y ocupa, es un ejemplo de la relación existente entre la emergencia de formas y contenidos artísticos y fenómenos sociales.

En todos los ámbitos de la vida social, el cuerpo ha resultado el objeto y "el centro de muchas preocupaciones tecnológicas e ideológicas. En la producción, en el consumo, en el ocio, en los espectáculos, en la publicidad, etc., el cuerpo se ha convertido en un objeto de tratamiento, de manipulación de mise-e-scene, de mercadeo. Es sobre el cuerpo donde convergen toda una retahíla de intereses sociales y políticos en la actual «civilización tecnológica" (J. M. Brohm, cit. en Bernard 1976: 13).

Sin duda, el cuerpo como material, lenguaje y tema del arte contemporáneo viene precedido de una teoría social, después del estructuralismo y las posturas sistémicas, que lo percibió antes como problema, desde el que afrontar las preguntas eternas en torno al ser humano y lo social. Así, la antropología ha dado cuenta de este vínculo. Geertz, por ejemplo, se ha ocupado de rescatar la relación entre la vida social y la emergencia de expresiones artísticas:

[...] la capacidad [...] para percibir el significado de las pinturas (o de poemas, melodías, edificios, cerámicas, dramas y estatuas) es, como todas las restantes capacidades humanas, un producto de la experiencia colectiva que la trasciende ampliamente, y donde lo verdaderamente extraño sería concebirla como si fuese previa a esa experiencia. A partir de la participación en el sistema general de las formas simbólicas que llamamos cultura es posible la participación en el sistema particular que llamamos arte, el cual no es de hecho sino un sector de ésta (Geertz 1994: 133).

La cuestión podría llevarnos mucho más allá incluso y no sería exagerado afirmar que «[...] en la vida cultural contemporánea, el arte ha llegado a ocupar un espacio asociado durante largo tiempo a la antropología, convirtiéndose en uno de los lugares principales para el seguimiento, la representación y la realización de los efectos de la diferencia en la vida contemporánea» (Marcus y Myers 1995: 1).

Desde entonces, la teoría social y antropológica ha tomado el cuerpo como objeto, con el argumento de que con él la persona se materializa como ser social. La fenomenología de Maurice Merleau-Ponty («El cuerpo se revela a sí mismo al mundo y a sí mismo», 1994), la idea de espacio social de Henri Lefebvre y el trabajo sobre lo cotidiano de Michel de Certeau comienzan este camino.

Más tarde, los conceptos de in-corporación desde Michel Foucault y habitus, a partir de Pierre Bourdieu, terminan de posibilitar que el cuerpo (el físico) cristalice como tema y proble- 
ma de las ciencias sociales, en el que se materializan y vinculan los tres tipos de nociones de cuerpo: el individual, el social y el político. A partir de aquí, el cuerpo es reconocido como una fundamental categoría unificadora de la existencia humana en todos los niveles: social, psicológico, biológico y cultural.

El surgimiento del arte performance se contextualizó en los sesenta junto a una aguda convulsión de las sociedades modernas. Esta década albergó la consolidación de la música popular y la televisión como fenómenos de masas, así como la revolución del 68, junto a otras revueltas relacionadas con la emergencia de identidades sexuales y raciales anteriormente silenciadas. El performance nació como arte para la resistencia, tendente a lo político, y se aleja del debate sobre individuos aislados y las reflexiones sobre el talento artístico (Warr 2006).

El arte de acción posibilita desde entonces la creación de un nuevo lenguaje artístico, más cercano a la realidad cultural e histórica. Se denomina performance al arte de acción que se populariza en los años setenta desde el ámbito anglosajón, reemplazando la acción para describir realizaciones artísticas públicas, sin la obligación de la participación de espectadores. Tiene que ver con ciertos aspectos de la situación teatral (con un mayor componente corporal: el cuerpo como agente del conocimiento), la danza, lo visual, ciertos comportamientos sociales y el acontecimiento como gesto límite de la vida. La performance es una manifestación artística que representa esa idea del work in progress, como reinvención continua y experimental de la obra-en-proceso de las artes escénicas. Además, la performance se caracteriza por la presencia en directo del cuerpo del artista como material: «El cuerpo soporte del discurso, duración en un tiempo limitado y acción, mostrados o expuestos en una presencia real y efímera o documental podrían ser principios que definan la performance, tanto si es el lenguaje explícito de la obra como si tan sólo es uno de sus elementos» (Torres 1997: 20).

\section{Submodalidades o tipos de videoperformances}

Cuando el vídeo de creación nació, a finales de los años sesenta, de manos del músico Nam June Paik, la unión de la música con el vídeo se convirtió en una vertiente prioritaria de experimentación para los nuevos artistas. La colaboración entre artistas como John Cage y Merce Cunningham en el Black Mountain College de Carolina del Norte ponen las primeras bases de la interacción e hibridación de medios hasta entonces separados como la danza, la performance y el vídeo.

De esto a utilizar el vídeo como forma de documentar acciones coreográficas hubo solo un paso, únicamente el primero de una fructífera relación entre dos medios que tienen en el tiempo 
y el movimiento los elementos de su más física materialidad.

Sin embargo, llegados a este punto, es necesaria una diferenciación de prácticas que, sin resultar un intento de jerarquización, sí responden a un deseo por diferenciar algo así como fases del vínculo creativo entre el medio vídeo y la performance, y por nombrar formas diversas de su interacción. Así, se proponen tres submodalidades.

La primera corresponde al registro en vídeo de la performance. A este nivel se le denomina con mucha frecuencia videoperformance, pero sería más correcto llamarle performance grabada, documentación de una performance (al igual que las fotografías propias de esta). Dicha submodalidad se basa en un empleo del video para complementar una supuesta desventaja o limitación de la performance, su carácter efímero. La grabación y reproducción en video de una acción acaba con su naturaleza única y da una forma, un formato (a la manera de cuadro, de grabación, de pieza comprable...) a la performance.

Un segundo paso o nivel de interrelación tiene que ver con las performances que utilizan el video como un material más para la realización necesaria de la acción propuesta. Podrían verse aquí como ejemplo el de la proyección (en forma de monitor, en forma de pantalla...) en una acción real ante el video e incluso ciertas formas de videodanza (empleo de la cámara y el monitor en la danza).
Es el caso de Acto sin título (1952), de John Cage y Merce Cunningham en el Black Mountain College, que incluía proyección de diapositivas y fragmentos de filmes de Rauschenberg, mientras Charles Olsen y Caroline Richards leían poesía, o de Variaciones $V$, performance audiovisual sin guion, representada en julio de 1965 en la Philharmonic Hall de Nueva York de Cunningham, Barbara Lloyd, David Tudor y Gordon Mumma, donde el espacio de la performance estaba cruzado con una red de células fotoeléctricas que cuando eran activadas por el movimiento de los bailarines producían efectos lumínicos, proyectaban imágenes...

También pueden citarse en esta modalidad las performances musicales multimedias de Laurie Anderson (por ejemplo, Wired of light and sound de 1983 o Stories from the Nerve Bible de 1992-1993) o los trabajos de Joan Jonas (Demora demora de 1972, Embudo de 1974) o Ulrike Rosenback (Don't believe I am an Amazon de 1975).

En este apartado pueden citarse también la mayoría de las prácticas de lo que se conoce como videodanza, piezas en las que las proyecciones se integran en los espacios donde se produce la coreografía. Los antecedentes de la videodanza, submodalidad consolidada de la videocreación, son dispersos y variados, desde el cine musical de los años treinta y cuarenta, dirigidos por realizadores como Busby Berkeley, a la experimentación de la danza moderna o las relaciones 
con el cine de artes marciales (el caso de Bruce Lee, por ejemplo).

Además, se ha producido una importante corriente de reflexión sobre la videodanza. A study in choreography for camera (1945), de Maya Deren, resulta un buen ejemplo de la importancia que la relación entre danza e imagen tenía ya antes del surgimiento oficial de las prácticas específicas de videodanza. Por su lado, Douglas Rosenberg con su teorización sobre la coreografía para medios audiovisuales y la relación entre danza y video, resulta uno de los autores más interesantes. Trabajos fácilmente reconocibles en los setenta como precursores de esta hibridación de medios son Earth Trilogy de Amy Greenfield (1971) y Dune Dance de Carolyn Brown (1978). Desde entonces, muchos han sido los intentos, desde variadas perspectivas, con que algunos creadores han tratado de explorar estos caminos artísticos.

En un tercer nivel, el de la submodalidad integral de videoperformance, el vídeo se utiliza no como mero registro sino explotando sus particulares propiedades expresivas como parte de la acción. El resultado es una pieza monocanal (con formato video, duración temporal determinada y reproducible) en la que tiene un importante papel la acción. En este caso, performance y dispositivo vídeo dialogan en igualdad. Las acciones son concebidas única o fundamentalmente para la cámara y no tienen sentido sin ella.
Con Bouncing in the corner 1 y 2 (Upside Down) (1968-1969) o Walking in an exaggerated manner around the perimeter of a squire (1967-1968), de Bruce Nauman, se juega con los límites del cuerpo bajos las condiciones que imponen los espacios cerrados reales (muros) o imaginarios (líneas pintadas en el suelo) en interacción con el encuadre de la cámara, como otro tipo de confín o espacio con un tratamiento oblicuo o basculante. El encuadre siempre fijo explora las variaciones del cuerpo y los límites de su alcance.

Pola Weiss es una de las figuras destacadas de la videocreación en todo el territorio latinoamericano, en concreto en México. Licenciada en Comunicación y Periodismo, encontró numerosas dificultades para desarrollar su trabajo desde su tesis de licenciatura en formato vídeo. Conoce a Nam June Paik y Shigeko Kubota en Nueva York en 1976 y con esta influencia funda su productora arTV, a través de la que realiza Flor cósmica un año después. Realiza trabajos en los que baila con la cámara de video, desarrollando un concepto de videodanza. En sus videocreaciones sobresalen sus emociones y experiencias personales, como Autovideato, su primera performance-video (1979), Caleidoscopio (1979) o El eclipse (1982).

El grupo de videoarte y performance Ruptz conoció una existencia efímera entre 1975 y 1978. Lo formaron Marc Borgers y Jean-Louis Sibille en Namur 
(Bélgica). A través de una decena de realizaciones, de las que apenas hay hoy unas cuantas fotos y videos, diversificaron las técnicas y los soportes para intentar reflexionar sobre la relación del consumidor-comprador con el objeto diseñado mediática y económicamente como obra de arte.

En esta tercera modalidad puede citarse el concepto de screendance de Rosenberg, una suerte de intento de recorporealizar la danza a través del video y la pantalla: «recorporealización se usa para describir una reconstrucción de la danza a través de la técnicas de la pantalla; al tiempo una construcción del cuerpo imposible, uno no afectado por la gravedad, las restricciones temporales o la muerte» (Rosenberg 2000).

La perspectiva de género resulta uno de los ámbitos desde donde se han abordado asuntos esenciales, como la deconstrucción del cuerpo, la identidad, la memoria y la subjetividad, con una conciencia del empleo íntegro de todas las posibilidades de la modalidad videoperformance. Ello ha dado lugar a obras que o bien reflexionan sobre la representación del cuerpo femenino en los medios de comunicación, o bien tratan de de- y re-construirlo para criticar su cosificación y recolocarlo como propiedad única de la mujer como ser social.

En el primer caso están Aujourd'hui (1999) y I'm not a girl who misses much (1986) de Pipiloti Rist, Dancing spanish dolls (2001) de Pilar Albarracín o Technology/transformation: wonder woman (1978) de Dara Birnbaum. En el segundo caso están los trabajos de Marina Núñez, que suponen una utilización paradigmática del medio, los de María Ruido con Ficciones anfibias (2005) o Zona franca (2009) y los de Susana Vidal Marí con Facing up II (2001), Peeling from the inside (2001), Risktaking I y Riskating II (2001) y Making my way (2000), todas obras en las que el tratamiento formal se adecua perfectamente al concepto de espacio entendido desde el punto de vista audiovisual en torno a la idea de encuadre.

\section{Territorios fronterizos}

Otros territorios que tradicionalmente se relacionan con la videoperformance se encuadran mejor en otras modalidades con entidad propia: es el caso de la videoinstalación o videoambiente y de la videoescultura, por ejemplo. Son las obras que explotan con fines artísticos el carácter de artefacto que posee el monitor, pero sin perder de vista una experimentación con el cuerpo.

En el caso de la videoinstalación, el trabajo Present continuos past (1974) de Dan Graham resulta célebre por su circuito cerrado de televisión, dispositivo para que el espectador cree una performance de reflexión sobre el tiempo. Con Glen Branca creó también Performance and stage-st utilizing two ways mirror and video time delay (1983), donde los espectadores y los 
músicos están dispuestos lado a lado con un espejo delante y otro detrás, de manera que músicos y espectadores están integrados en el reflejo del espejo; cada parte no puede reconocerse sin la imagen especular de la otra, lo que genera un sentido particular y compartido de unidad de sus cuerpos, presencias y funciones en la performance. Proyecciones de video con un retraso de seis minutos terminan por diluir las identidades y los tiempos.

Con Command performance (1974), Vito Acconci crea un bucle de representación entre el público, el artista y la obra de arte, que consiste en una serie de monitores que muestran representaciones constantemente cambiantes del artista y el público. El visitante se sienta en un taburete transversal a un monitor en el que Acconci se presenta al público. Una cámara filma al visitante sin que este se dé cuenta mientras observa a Acconci a través de la pantalla e inmediatamente después aparece en el monitor convirtiéndose así en el sujeto/objeto de la obra.

En Or-phelia (1982) de Ulrike Rosenback se simulan las funciones corporales con tres pantallas de video encajadas en el suelo que muestran corrientes de agua y fluidos orgánicos.

Más recientemente, los trabajos de Mona Hatoum como Pull (1995) trabajan sobre una interactividad entre artista-espectador que recuerda a los mejores happenings.

En cuanto a la videoescultura, Tony Oursler con I can't hear you (1995), co- loca monitores como rostros o bustos que hablan (pero no se escuchan) entre sí, y sigue la línea de experimentos de Charlotte Moorman con Nam June Paik como TV Bra for Living Sculpture (1969) y TV Cello (1971).

Estos son ejemplos de frontera difusa que también subvierte la relación del espectador de los medios masivos por el hecho de que se materialice a través de un monitor.

Por último, puede citarse el empleo del video en el campo del bodyart, submodalidad del arte de acción donde podrían destacarse a Orlan y Stelarc.

El trabajo de la primera se centra en la reflexión del cuerpo como construcción social, en la que la grabación y retransmisión en vídeo de sus transformaciones quirúrgicas (lo que ella llama «arte carnal») suponen un medio para introducir o implicar al espectador en el directo de la performance que, por motivos de su realización en una sala de operaciones, está, en principio, excluido. Sin duda, «desde su perspectiva, las tecnologías modernas han vuelto obsoleta la noción del cuerponatural» (Davis 2007: 137). En el caso de Stelarc, la relación del cuerpo con la tecnología se lleva a cabo desde la ampliación de los sentidos y miembros del cuerpo, con lo que el medio vídeo se emplea como extensión de la visión o empleando la materialidad de los cables, las conexiones y los monitores vídeo. 


\section{Bibliografía}

Acconci, Vito (2009). «En torno a la acción». Fin del arte. Teorías. Conceptos. Testimonios. <http://artecontempo. blogspot.com/2005/10/vito-acconci. html>. [Consulta: 7 de marzo del 2012].

Bernard, Michel (1976). Le corps. París: Jean-Pierre Delarge.

Butler, Judith (2002). Cuerpos que importan. Buenos Aires: Paidós.

Davis, Kathy (2007). «Mi cuerpo es arte: ¿La cirugía cosmética como una utopía feminista?», en El cuerpo a la carta. Estudios culturales sobre cirugía cosmética. México: La Cifra.

Deleuze, Gilles y Felix Guattari (1998). Mil mesetas. Valencia: Pre-textos.

Foucault, Michel (1990). Tecnologías del yo. Barcelona: Paidós.

Geertz, Clifford (1994). «El arte como sistema cultural», en Conocimiento local. Ensayo sobre la interpretación de las culturas. Barcelona: Paidós.

Goldberg, RoseLee (1998). Performance: Live art since the 60s. Londres: Thames and Hudson.

Gómez Peña, Guillermo (2005). «En defensa del arte del performance».
Horizontes Antropológicos 24. Porto Alegre: IFCH-UFGRS.

Marcus, George E. y Fred R. Myers (eds.) (1995). «The traffic in art and culture: An introduction», en Marcus, George. E. The traffic in culture. Refiguring art and anthropology. Berkeley: University of California Press.

Merleau-Ponty, Maurice (2004). Fenomenología de la percepción. Barcelona: Península.

Pérez Ornia, Juan Ramón (1991). El arte del video. Madrid: Ediciones Serbal/ RTVE.

Rosenberg, Douglas (2000). «Essay on screen dance». Ponencia presentada en el Simposio «Dance for the Camera», organizado por el Departamento de Arte de la Universidad de Wisconsin. Madison, Wisconsin.

Torres, David (1997). «La vigencia oculta de la performance». Lápiz 132. Revista Internacional de Arte. Madrid: Ediciones L.

Warr, Tracey (ed.) (2006). El cuerpo del artista. Barcelona: Phaidon. 